\title{
Factors affecting small and medium enterprises (SMEs) continuance intention to adopt e-commerce in Jordan
}

\author{
Lubna A. Hussein *, Ahmad Suhaimi Baharudin \\ School of Computer Sciences, Universiti Sains Malaysia, 11800 USM, Penang, Malaysia
}

\section{A RT ICLE INFO}

\section{Article history:}

Received 18 December 2016

Received in revised form

23 March 2017

Accepted 25 March 2017

\section{Keywords:}

TOE framework

SMEs in Jordan

E-commerce continuance intention

\begin{abstract}
A B S T R A C T
E-Commerce plays important roles in developed and developing countries. Many SMEs in developing countries could benefit enormously from ecommerce for their business activities. Despite the availability of both broadband communication and multiple internet service providers (ISPs), the adoption rate is still very low as compared to other developing nations in the region. Data was collected from manufacturing SMEs in Jordan, using a survey method. A total of 210 data was obtained from respondents. Data was analyzed using Smart PLS 3. It was found that both relative advantages and IT competency have an impact on Jordan manufacturing SMEs continuance intention to adopt e-commerce. These findings could help SMEs, owner/managers of SMEs, to take necessary action to ensure that their organizations will continue to use e-commerce in their daily business activities.
\end{abstract}

(C) 2017 The Authors. Published by IASE. This is an open access article under the CC BY-NC-ND license (http://creativecommons.org/licenses/by-nc-nd/4.0/).

\section{Introduction}

Electronic commerce defined by Turban et al. (2008) as the process of buying, selling, transferring, or exchanging products, services, and/or information through computer networks, principally the Internet. Adoption of electronic commerce offers a great opportunity for SMEs to gain many benefits to organizations such as: (i) improved productivity by creating new relationships through customer/ supplier and other strategic partners (ii) improved cost saving in transaction costs, (iii) increases the speed of business, (iv) improved transaction efficiencies ( $v$ ) access a wide range of markets. The adoption of e-commerce by SMEs manufacturers has been unexpectedly slow, although its importance has been recognized by the industry for a long time. Over the last decade, while many manufacturers have expressed an interest in incorporating e-commerce technology into their existing platforms, very little has actually continued to adopt e-commerce with high level.

However, many studies such as Al-Dmour and AlSurkhi, (2012) and Alrousan (2015) argued that the diffusion and adoption of e-commerce by Jordanian SMEs are slower than and far behind larger

\footnotetext{
* Corresponding Author.

Email Address: lubnafatlawi@gmail.com (L. A. Hussein) https://doi.org/10.21833/ijaas.2017.04.016

2313-626X/C 2017 The Authors. Published by IASE.

This is an open access article under the CC BY-NC-ND license

(http://creativecommons.org/licenses/by-nc-nd/4.0/)
}

organizations. SMEs development of e-commerce is very important to Jordan's economic growth as ecommerce is considered as a significant component strategy to survive in the market as technology adoption, provides many great benefits for SMEs that makes them able to have the ultimate competitive advantage such as the ability to compete with larger organizations.

In this regards, there is a need to identify and critically examine significant factors that contribute to the sustainability of SMEs' business based on ecommerce in Jordan that allow its continuous growth despite the challenging competitive landscape. For SMEs specifically, the role of the Internet as an SME business strategy needs to be researched, particularly in strategic business development and the discovery of new business opportunities. It has been asserted that Internet technologies have entirely eased the way towards an electronic economy that enables innovative business tactics (Lecic-Cvetkovic et al., 2016; Ramayah et al., 2016). Therefore, this study aims to examine the state of use of e-commerce and factors that may affect ecommerce continuance intention in Jordanian SMEs.

\section{Research model and hypothesis of this study}

This research design mainly from the Technology-Organization-Environment (TOE) framework by Tornatzky and Fleischer (1990). TOE framework is consistent with Rogers' (2003) diffusion of innovation theory as it focuses on both 
internal and external characteristics of the organization, as well as technological characteristics in the study of drivers for new technology diffusion as shown by Ahmed et al. (2015). TOE framework can be combined with DOI theory. Five factors of DOI theory (Relative advantage, Compatibility, Complexity, Trialability, Observability) are used in the technological context to describe the adoption depends on the pool of technologies inside and outside the organizations. Oliveira and Martins (2010) argued that most empirical studies use the TOE framework of IT adoption on organization level, because it has a solid theoretical basis, consistent empirical support, and the potential for the application of IT adoption. So that most of the studies use DOI theory with the TOE framework to become better able to explain intra-firm innovation adoption. Review of organizational technology adoption indicates that SMEs are likely to consider many factors when contemplating an e-commerce. In this study, the proposed model is built based on literature review. Four independent factors influence on dependent factor continuance intention to adopt e-commerce, see Fig. 1. Literature review of IS studies by Santhanamery and Ramayah (2013) that defined continuance intention as "user's intention to continue use or long term usage intention of technology in order to make sure that the technology is better from the previous one". For this study continuance can be defined as the intention of continuing use of an organization e-commerce to share product information, contact with supplier and customers, and conduct business transactions through telecommunications networks.

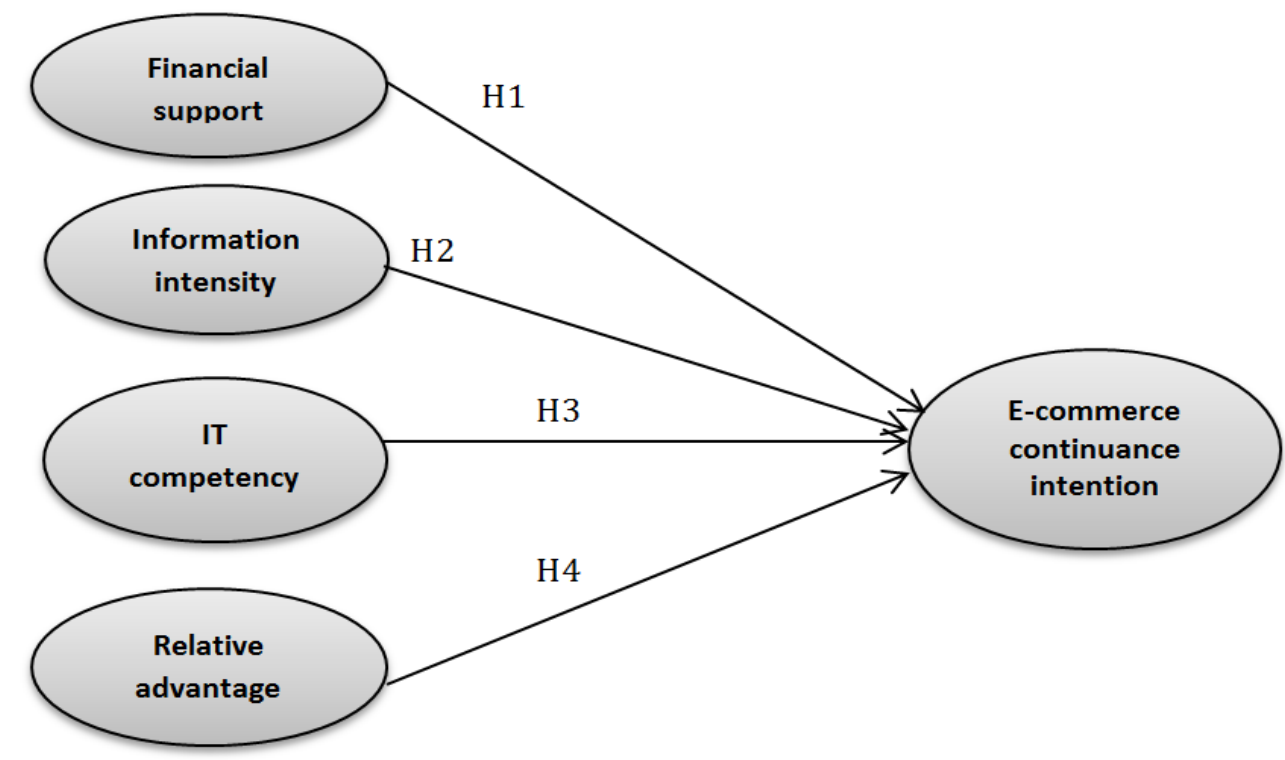

Fig. 1: Conceptual Research Framework

\subsection{The relationship between financial support and e-commerce continuance intention}

Financial support is an important factor for the adoption of different IS. The researchers Bao and Sun (2010), Rowe et al. (2012), Ifindo (2012) explained that the lack of financial resources place constraints on the e-commerce implementation effort and often lead to the slow adoption. The term of financial support in this research is defined as the financial level of IT infrastructure and IT Staff to implement and adopt e-commerce. Thong (2001) and Zhu et al. (2006) were found financial support is a significant key for IT adoption and supported positively the adoption.

To ensure success for e-commerce adoption, SMEs should provide adequate financial resources that will be used to purchase essential infrastructure, and to training current employees for using e-commerce technology. Cosgun and Dogerlioglu (2012) found financial support as major determined and have significant effects on ecommerce activities. Therefore, this study hypothesizes as:
H1: Financial support has a positive impact on ecommerce continuance intention

\subsection{The relationship between information intensity and e-commerce continuance intention}

Thong (1999), Whittaker et al. (2006) and Mndzebele (2012) illustrated the information intensity as "refers to the degree of information that is present in the product or service of an organization". According to Whittaker et al. (2006), Mndzebele (2012) the information content of a product is the useful information within a product that is received and understood by the user of that product. Whittaker et al. (2006) shown that when there is enough information about a product, it is likely that the product will be adopted. Some product is difficult to explain the information about it and this can be very difficult to adopt e-commerce by organization. Because complicated information may lead to many difficulties that prevent the adoption. Literature reviews were found information intensity encourages innovation adoption. For example, AlQirim (2007) who investigated the impact of 
information intensity on the adoption of e-commerce among SMEs in New Zealand found that the information intensity was influenced by the adoption of websites. Therefore, this study hypothesizes as:

$\mathrm{H} 2$ : Information intensity has a positive impact on ecommerce continuance intention

\subsection{The relationship between IT competency and e-commerce continuance intention}

Literature reviews of different IS studies found IT competency as an important key for different IS adoption, because is based on IT infrastructure and resources offered by IT professionals. Salwani et al. (2009), Khan et al. (2010), Oliveira and Martins (2010) and Wang et al. (2010) all of these studies and more argued that IT competency is very important for adoption. IT professionals are understood as having the necessary knowledge and skills for implementing e-commerce applications, they can using it easier than the other (Ifindo, 2012). The term of IT competency in this research defined as the technological readiness that based on IT infrastructure, skills and knowledge offered by an IT professional. According to Ratanapoophun and Lee (2010) mentioned that IT competency has a significant effect on ICT adoption, also Kuan and Chau (2001) argued IT competency as significant and necessary to support the use of EDI for small firms in Hong Kong. Similar to Zhu and Kraemer (2005), Zhu et al. (2006) were founded IT competency as a significant adoption facilitator; to adopt e-businesses across countries. Soares-Aguiar and Palma-Dos-Reis (2008) were founded IT competency a significance of e-procurement systems adoption. Therefore, this study hypothesizes as:

H3: IT competency has a positive impact on ecommerce continuance intention

\subsection{The relationship between relative advantage and e-commerce continuance intention}

According to Rogers (2003), relative advantage is "the degree to which an innovation is perceived as being better than the idea it supersedes". Rogers argued that the innovation adopters rely on the nature of innovation to determine the type of relative advantage in addition to the characteristics of the adopters themselves. Previous studies, for example, Lu et al. (2009), Wang et al. (2010), Almoawi and Mahmood (2011) found relative advantage as the best predictor of adoption of different technologies. The researchers explain the relative advantage of e-commerce is important, because it describes the amount of benefits and predicates an organization will be an experience for adopting or rejecting a new innovation or technology. Also Elmazi et al. (2011) determine that relative advantage is the rate level of management understanding of the benefit of e-commerce can provide to the organization. Different literature reviews founded relative advantage is significant to adopt IS studies such as Looi (2005), Al-Qirim
(2007), Hussin et al. (2008), Ramadani et al. (2009) and Wang et al. (2010). Most of IS adoption researchers have shown that the relative advantage is positively related to the adoption decision. Ramayah et al. (2016) mentioned that relative advantage has a significant effect on website continuance intention in Malaysian SMEs. Sin et al. (2016) founded relative advantage influence towards implementation of e-commerce among SMEs.

Therefore, this study hypothesizes as:

H4: Relative advantage has a positive impact on ecommerce continuance intention

\section{Methodology}

This study used simple random sampling procedure to select a sample that represents the entire population. According to Kenneth et al. (2012), a simple random sample is used when a population is heterogeneous, making it the most appropriate sample to come up with the target sample. In this study the manufacturing SMEs is selected, because Manufacturing SMEs plays an important role in economic growth in Jordan, and the gross domestic product amounted (GDP) to about $24 \%$ manufacturing sector in Jordan. Also during the first three quarters of the year 2014 to be the second largest economic sector after sector services and $25 \%$ of the total Jordanian national product. Data were collected from SMEs that have at least (email or website) and intended to continue using e-commerce. Self-administered questionnaire, which was sent personally by the researcher to the respondents to gain more. The returned data that used is 210 samples. Sekaran and Bougie (2016) argued that sample size that is larger than 30 and less 500 are appropriate for most research, so the sample size is acceptable for this study. All the variables and the question items were adapted from literature reviews and were modified to match the objective of this study. Some major scale items are based on different degrees via the 7-point Likertscale being utilized for all the responses with 1=Strongly disagree, $2=$ Disagree, $3=$ Slightly disagree, $4=$ Neither agree or disagree, $5=$ Slightly agree, $6=$ agree, $7=$ Strongly agree.

\section{Result}

The software SmartPLS 3 was used by Ringle et al. (2015) for the data analysis. The data were analyzed in two steps:

\subsection{Measurement model}

First, the convergent validity was examined. Average Variance Extracted (AVE) is a method used to estimate the convergent validity. The AVE must exceed than 0.5 to gain an acceptable convergent validity. Composite reliability (CR) must be 0.7 or above is deemed to be acceptable. Main loading 
should be 0.7 (Hair et al., 2014). Based on result on Table 1, indicators loading for all items exceeded the recommended value of 0.5 suggested (Hair et al., 2014), but three items (FS1, IT4, ITC2) were deleted due to low factor loading. AVE were in the range of
0.745 to 0.874 , which exceeded the recommended value greater than 0.50 , and the $\mathrm{CR}$ ranged from 0.931 to 0.965 , which exceeded the recommended value of 0.7 recommended by Hair et al. (2014). Table 1 shows the results of measurement model.

Table 1: Goodness-of-fit measurement model $(n=210)$

\begin{tabular}{|c|c|c|c|c|}
\hline Latent variable & Question Items & Loading & AVE & Composite Reliability (CR) \\
\hline \multirow{7}{*}{ CI } & CI1 & 0.931 & \multirow{7}{*}{0.873} & \multirow{7}{*}{0.965} \\
\hline & $\mathrm{CI} 2$ & 0.937 & & \\
\hline & $\mathrm{CI} 3$ & 0.945 & & \\
\hline & CI4 & 0.924 & & \\
\hline & FS2 & 0.943 & & \\
\hline & FS3 & 0.961 & & \\
\hline & FS4 & 0.950 & & \\
\hline \multirow{3}{*}{ II } & III & 0.952 & \multirow{3}{*}{0.818} & \multirow{3}{*}{0.931} \\
\hline & II2 & 0.825 & & \\
\hline & II3 & 0.932 & & \\
\hline \multirow{3}{*}{ ITC } & ITC1 & 0.962 & \multirow{3}{*}{0.874} & \multirow{3}{*}{0.954} \\
\hline & ITC3 & 0.871 & & \\
\hline & ITC4 & 0.968 & & \\
\hline \multirow{5}{*}{ RA } & RA1 & 0.875 & \multirow{5}{*}{0.745} & \multirow{5}{*}{0.936} \\
\hline & RA2 & 0.831 & & \\
\hline & RA3 & 0.887 & & \\
\hline & RA4 & 0.900 & & \\
\hline & RA5 & 0.818 & & \\
\hline
\end{tabular}

Second, Discriminant validity is tested by means of assessment like Fornell Larcker, Cross loadings and the Heterotrait -monotrait ratio (HTMT). Fornell and Larcker (1981) mentioned that discriminant validity, is the square root of the AVE when compared against the correlations of the other constructs, if the AVE extracted is greater than its correlations with all the other constructs then discriminant validity has been established, see Table 2.

Table 2: Fornell-larcker criterion $(\mathrm{n}=210)$

\begin{tabular}{|c|c|c|c|c|c|}
\hline & $\mathrm{CI}$ & FS & II & ITC & RA \\
\hline $\mathrm{CI}$ & 0.934 & & & & \\
\hline $\mathrm{FS}$ & 0.235 & 0.951 & & & \\
\hline II & -0.091 & 0.220 & 0.905 & & \\
\hline ITC & 0.323 & 0.299 & 0.070 & 0.935 & \\
\hline RA & 0.523 & 0.385 & -0.056 & 0.340 & 0.863 \\
\hline
\end{tabular}

As shown in Table 2, this study presents that the square root of AVEs is greater in all cases than the off-diagonal elements in their corresponding row and column, so that the required discriminant validity by Fornell-locker has been achieved. As noted in SmartPLS2 documentation, although examination of cross-loadings and use of the FornellLarcker criterion is accepted methods for assessing the discriminant validity of a PLS model, these methods have shortcomings. Henseler et al. (2015) used simulation studies to demonstrate that lack of discriminant validity is better detected by the heterotrait-monotrait (HTMT) ratio, they developed, and this method is used in Smart PLS3.

The HTMT ratio is the geometric mean of the heterotrait-heteromethod correlations (i.e. the correlations of indicators across constructs.

Measuring different phenomena divided by the average of the monotrait-heteromethod correlations (i.e. the correlations of indicators within the same construct). Averaging using the geometric mean is necessary because there are two monotraitheteromethod submatrices (sets of within-construct correlations), for example, when there are two constructs. According to Garson (2016), a well-fitting model, heterotrait correlations should be smaller than monotrait correlations, meaning that the HTMT ratio should be below 1.0, indicate a lack of discriminant validity. As shown on Table 3 , the threshold value is considered close to 0.85 . The constructs in the study satisfy the discriminant validity assessment on the basis of HTMT.

\begin{tabular}{|c|c|c|c|c|c|}
\hline & $\mathrm{CI}$ & FS & II & ITC & RA \\
\hline CI & & & & & \\
\hline FS & 0.246 & & & & \\
\hline II & 0.078 & 0.270 & & & \\
\hline ITC & 0.342 & 0.320 & 0.123 & & \\
\hline RA & 0.546 & 0.405 & 0.084 & 0.370 & \\
\hline
\end{tabular}

\subsection{Assessment of structural model}

The structural model provides the relationship between latent variables in the research model. The following criteria facilitate this assessment: Coefficient of determination $\left(\mathrm{R}^{2}\right)$, cross-validated redundancy $\left(\mathrm{Q}^{2}\right)$, and path coefficients (Hair et al., 2014). Table 4 shown the path coefficient of items. 
Table 4: Significance result of path coefficients $(n=210)$

\begin{tabular}{ccccccc}
\hline Hypothesis & Relationship & Beta value & Sample Mean & Std. Error & t-value & P Values \\
\hline H1 & FS - $>$ CI & 0.030 & 0.029 & 0.067 & 0.453 & 0.325 \\
H2 & II -> CI & -0.084 & -0.092 & 0.068 & 1.236 & 0.109 \\
H3 & ITC -> CI & 0.166 & 0.166 & 0.052 & $3.211^{* *}$ & 0.001 \\
H4 & RA - CI & 0.450 & 0.459 & 0.066 & $6.812^{* * *}$ & 0.000 \\
\hline \multicolumn{7}{c}{ Note: ${ }^{*} \mathrm{p}<0.05,{ }^{* *} \mathrm{p}<0.01,{ }^{* * *} \mathrm{p}<0.001$}
\end{tabular}

The result shown the positive relationship of IT competency on e-commerce continuance intention with $\beta=0.166$ and significant with $t$-value $=3.211$ and $p<0.01$, also a positive relationship of relative advantage of e-commerce continuance intention with $\beta=0.450$ and significant with $t$-value $=6.812$ and $\mathrm{p}<0.001$.

As shown in Fig. $2 \mathrm{R}^{2}$ value for website continuance intention is 0.304 suggesting that $30.4 \%$ of the variance in e-commerce continuance intention can be explained by the SMEs'.

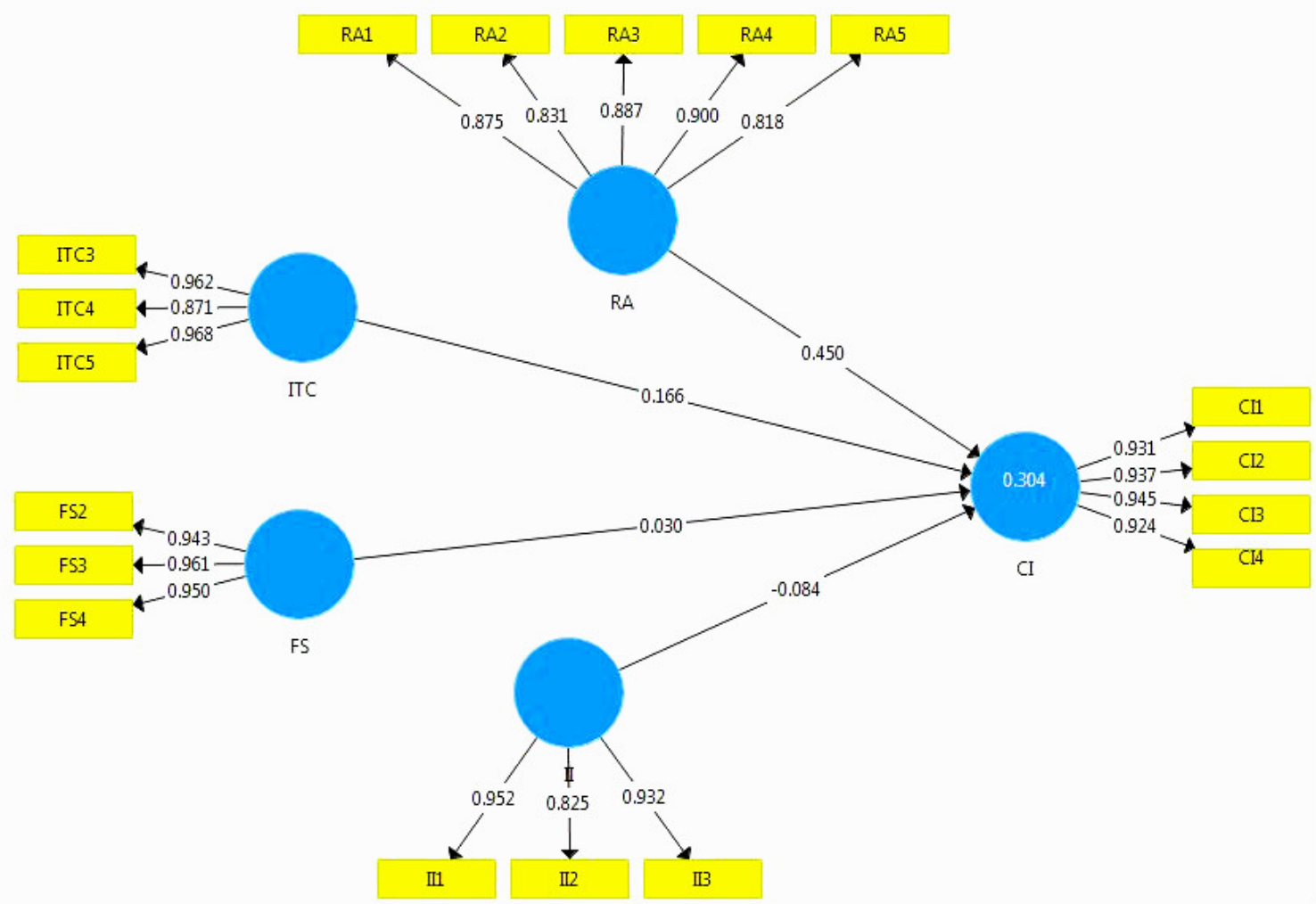

Fig. 2: PLS-Path digram $(\mathrm{n}=210)$

According to Ramayah et al. (2016), predictive sample reuse technique, popularly known as the Stone-Geisser's $\mathrm{Q}^{2}$, can be applied as a criterion for predictive relevance besides looking at the magnitude of the $\mathrm{R}^{2}$. Henseler et al. (2009) also utilized this measure to assess the research model's capability to predict. Based on the blindfolding procedure as presented by Hair et al. (2014), Q ${ }^{2}$ evaluates the predictive validity of a model via PLS. $\mathrm{Q}^{2}$ values larger than zero indicate that the exogenous constructs have predictive relevance for the endogenous construct. Fig. 3, shown $\mathrm{Q}^{2}$ for ecommerce continuance intention $(=0.247)$, that mean the research model has good predictive relevance.

Finally, Table 5 shown the summary of hypothesis, that IT competency and relative advantage are supported in this study, otherwise financial support and information intensity are not supported.

\section{Discussion}

The result of the study is used to answer the question about the factors that effect on e-commerce continuance intention by SMEs in Jordan. There are four independent variables: Relative advantage, financial support, IT competency and information intensity used to investigate the relationship with ecommerce continuance intention. Among these four variables, two variables are not significant: financial support and information intensity, and another two variables: Relative advantage and IT competency are significant. Relative advantage is the most significant factor that affects e-commerce continuance intention. This similar to the previous studies such as Alam et al. (2011) and Ahmed et al. (2015) suggested when e-commerce as perceived relative advantage as being better than the idea it supersedes, and beneficial to SMEs, its adoption is more likely. 
Relative advantage is benefited by SMEs overall reducing costs, expand global market and improve public relations to improve the image as presented by Alam et al. (2011). Also Ramayah et al. (2016) found relative advantage is a significant factor on website continuance intention in Malaysian SMEs, the researchers mentioned that the perceived relative advantage of having an online presence, the greater the website continuance intention is in SMEs. Sin et al. (2016) mentioned that relative advantage of E-commerce is not only to increase sales, global market share, reduced costs, exploit new business prospects but also will improve relationships with dealers and companion. IT competency is another significant factor that has a positive effect on ecommerce continuance intention, similar to previous studies that undertaken e-commerce, such as Salwani et al. (2009).

Table 5: Summary of hypothesis analysis $(n=210)$

\begin{tabular}{lcc}
\hline & Hypotheses & Results \\
\hline $\mathrm{H}_{1}$ & FS $->\mathrm{CI}$ & Not Supported \\
$\mathrm{H}_{2}$ & II $->\mathrm{CI}$ & Not Supported \\
$\mathrm{H}_{3}$ & ITC $->\mathrm{CI}$ & Supported \\
$\mathrm{H}_{4}$ & $\mathrm{RA}->\mathrm{CI}$ & Supported \\
\hline
\end{tabular}

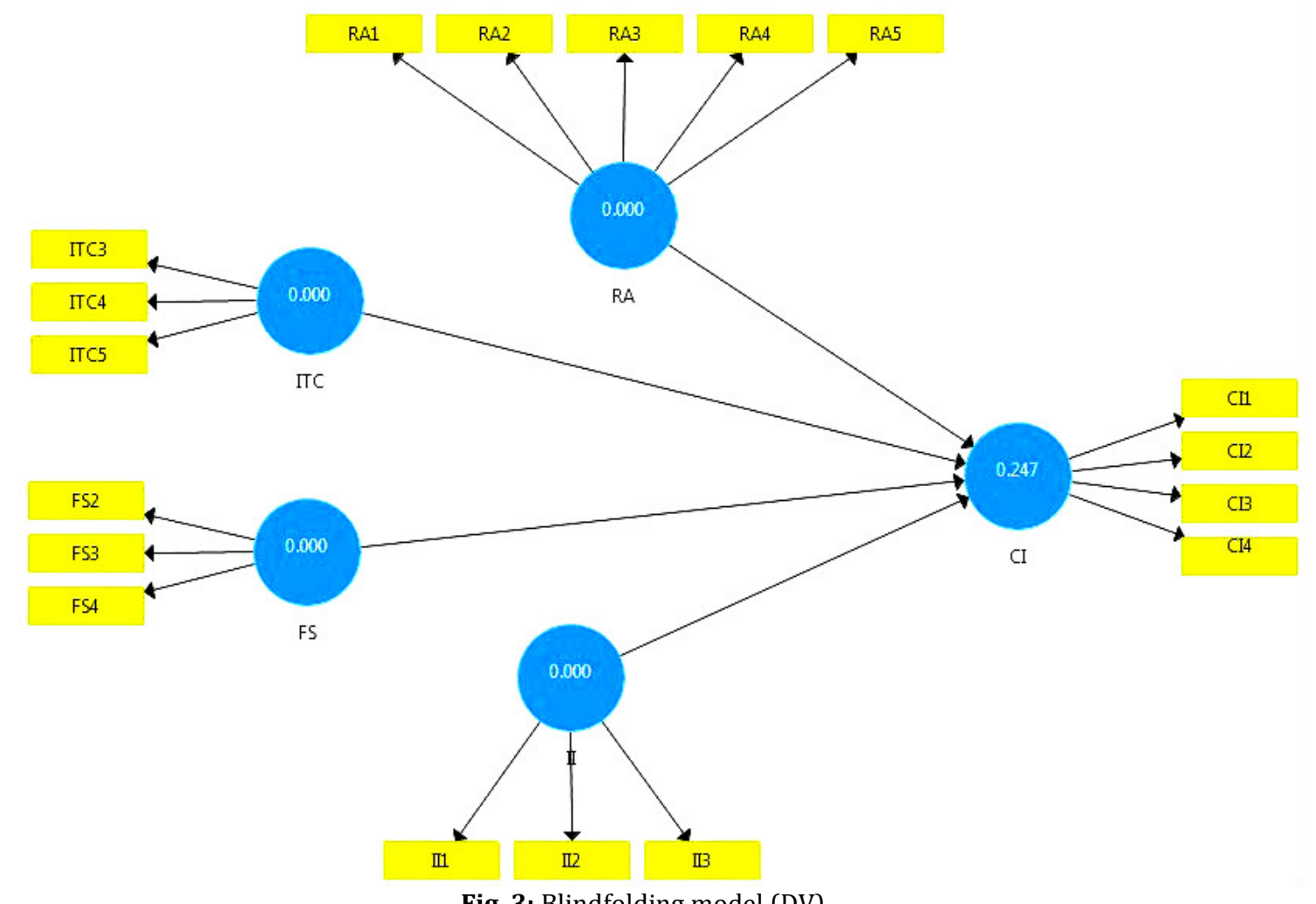

Fig. 3: Blindfolding model (DV)

Also, different IS studies were found IT competency as an important key for different IS adoption, because is based on IT infrastructure and resources offered by IT professionals Zhu and Kraemer (2005), Zhu et al. (2006), Oliveira and Martins (2010) and Wang et al. (2010). All of these studies and more argued that IT competency is very important for adoption, because of e-commerce continuance is necessary for IT infrastructure to understand installed network technologies for ecommerce, and IT professionals to understood as having the necessary knowledge and skills for implementing e-commerce applications. Financial resources and information intensity are two factors that have no significant effect for e-commerce continuance adoption in Jordan. This study for financial support is similar to which found financial support Tan and Eze (2008) and Ghobakhloo et al. (2011) insignificant. This is might be financial resources may be important for SMEs that want to start use of internet and buy a laptop or PC, however it is at the implementation stage of e-commerce adoption where the organization seeks the availability of necessary funds and expertise.

Different studies found information intensity not significant effect on the e-commerce adoption and different IS studies such as Al-Qirim (2007), AlQahtani and Wamba (2012). This may be explained according to early studies on IT adoption suggest that sectors operating in information-intensive environments (e.g. financial services) are more likely to adopt IT innovations (Yap, 1990).

\section{Conclusion}

This study builds upon prior research studies, but is different in importance in a way that it analyzes factors that may influence e-commerce continuance intention by Jordanian SMEs. For this purpose, a sample of 210 SMEs in the Jordan was investigated. The research was done based on the TOE framework that was developed based on previous studies. Four factors that were driving of e-commerce continuance intention were identified through the use of Smart PLS3. The finding shows that relative advantage, IT 
competency statistically significant factors of ecommerce continuance intention. On the other hand, financial support and information intensity did not seem to influence of e-commerce. The empirical data can be used to extend the body of knowledge for adoption \& diffusion research in developing countries, particularly in Jordan. In general, the study provides more understanding of owner's/managers' of SMEs perceptions about ecommerce continuance intention in their businesses.

\section{Acknowledgement}

The authors would like to sincerely thank the School of Computer Sciences, Universiti Sains Malaysia (USM) as this research has been supported by the Research University Grant (RUI) [Account Number: 1001/PKOMP/811251] and Graduate on Time (GoT) Intensive Research Grant [Account Number: 1001/PKOMP/823131] from the Universiti Sains Malaysia.

\section{References}

Ahmed SZ, Abu Baker RA, Faziharudean TM, and Zaki KA (2015). An Empirical Study of Factors affecting e-commerce adoption among small and medium-sized enterprises in a developing country: Evidence from Malaysia. Information Technology for Development, 21(4): 555-572.

Alam S, Ali MY, and Jani MF (2011). An empirical study of factors affecting electronic commerce adoption among SMEs in Malaysia. Journal of Business Economics and Management, 12(2): 375-399.

Al-Dmour H and Al-Surkhi MM (2012). Factors affecting SMEs adoption on internet-based information systems in businessto-business (B2B) and the value-added on organization's performance. Jordan Journal of Applied Science, 14(1): 181200.

Almoawi ARNA and Mahmood R (2011). Applying the OTE model in determining the e-commerce adoption on SMEs in Saudi Arabia. Asian Journal of Business and Management Sciences, 1(7): 12-24.

Al-Qahtani S and Wamba FS (2012). Determinants of RFID technology adoption intention in the Saudi retail industry: An empirical study. In the IEEE 45 th Hawaii International Conference on System Sciences (HICSS'12), IEEE, Maui, USA: 4720-4729. https://doi.org/10.1109/HICSS.2012.202

Al-Qirim N (2007). The adoption and diffusion of E-Commerce in developing countries: The case of an NGO in Jordan. Information Technology for Development, 13(2): 107-131.

Alrousan MK (2015). E-commerce adoption by travel agencies in Jordan. Ph.D. Dissertation, Cardiff Metropolitan University, Wales, UK.

Bao J and Sun X (2010). A conceptual model of factors affecting adoption by SMEs in China. In the $4^{\text {th }}$ International Conference on Mmanagement of E-Commerce and E-Government (ICMeCG), IEEE, Chengdu, China: 172-175. https://doi.org/10.1109/ICMeCG.2010.43

Cosgun V and Dogerlioglu O (2012). Critical success factors affecting e-commerce activities of small and medium enterprise. Information Technology Journal, 11(12): 16641676.

Elmazi I, Vukaj H, Gega E, and Elmazi L (2011). Information technology and its effects in SME. The case of Albania. International Journal of Management Cases, 13(4): 291-298.
Fornell C and Larcker DF (1981). Evaluating structural equation models with unobservable variables and measurement error. Journal of Marketing Research, 18(1): 39-50.

Garson D (2016). Partial least squares: Regression structural equations models. Statistical Publishing Associates, Asheboro, USA.

Ghobakhloo M, Aranda D, and Amado J (2011). Adoption of ecommerce applications in SMEs. Industrial Management and Data Systems, 111 (8): 1238-1269.

Hair JF, Sarstedt M, Hopkins L, and Kuppelwieser VG (2014). Partial least squares structural equation modeling (pls-sem): an emerging tool in business research. European Business Review, 26(2): 106-121.

Henseler J, Ringle C, and Sinkovics R (2009). The use of partial least squares path modeling in international marketing. Advances in International Marketing 20: 277-320.

Henseler J, Ringle CM, and Sarstedt M (2015). A new criterion for assessing discriminant validity in variance-based structural equation modeling. Journal of the Academy of Marketing Science, 43(1): 115-135.

Hussin H, Nor RM, and Suhaimi MA (2008). Perceived attributes of e-commerce and the adoption decision: The case of Malaysian SMEs. Journal of Teknologi Maklumat and Multimedia, 5(1):107-125.

Ifindo P (2012). Facilitating the intention to expand e-business payment systems use in nigerian small firms: An Empirical analysis. In: Ifindo P (Ed.), E-Business-Applications and Global Acceptance: 19-40. InTech, Rijeka, Croatia.

Kenneth W, Rebecca N, and Eunice A (2012). Factors affecting adoption of electronic commerce among small medium enterprises in kenya: Survey of tour and travel firms in nairobi. International Journal of Business, Humanities and Technology, 2(4): 76-91.

Khan MJ, Dominic PDD, Khan A, and Naseebullah (2010). Adoption of e-commerce in Malaysia and its affect on the business performance: An organizational perspective. In the Conferance of Information Technology (ITSim), IEEE, kuala lumpur, Malesia, 1: 1-5. https://doi.org/10.1109/ ITSIM.2010.5561340

Kuan KKY and Chau PYK (2001). A perception-based model for EDI adoption in small businesses using a technologyorganization-environment framework. Information and Management, 38(8): 507-521.

Lecic-Cvetkovic D, Omerbegovic-Bijelovic J, Zaric S, and Janicic R (2016). E-banking application in business companies - a case study of Serbia. Information Development, 32(4): 762-776.

Looi HC (2005). E-Commerce adoption in Brunei Darussalam: Quantitative analysis of factors influencing its adoption. Communications of the Association for Information Systems, 15(3): 61-81.

Lu Y, Quan J, and Cao X (2009). The perceived attributes of Wi-Fi technology and the diffusion gap among university faculty members: A case study. Communications of the Association for Information Systems, 24(1): 69-88.

Mndzebele N (2012). Information intensity and its effect on EC adoption. International Journal of Advanced Computer Technology, 2(3): 105-108.

Oliveira T and Martins MF (2010). Understanding e-business adoption across industries in European countries. Industrial Management and Data Systems, 110(9): 1337-1354.

Ramadani B, Kawalek P, and Oswaldo L (2009). Knowledge management and enterprise systems adoption by SMEs: Predicating SMEs' adoption of enterprise systems. Journal of Enterprise Information Management, 22(1/2):10-24.

Ramayah T, Ling SN, Seyedeh KT, and Syed AR (2016). Factors influencing SMEs website continuance intention in Malaysia. Telematics and Informatics, 33(1): 150-164. 
Ratanapoophun S and Lee SM (2010). The relationship between business factors affecting information and communication technology adoption in the Thai banking industry. The Thai Journal Citation Index Centre, 9(2): 133-145.

Ringle CM, Wende S, and Becker JM (2015). SmartPLS 3. SmartPLS $\mathrm{GmbH}$, Bönningstedt, Germany. Available online at: http://www.smartpls.com.

Rogers EM (2003). Diffusion of innovations. The Free Press. NY, USA.

Rowe F, Truex D, and Huynh MQ (2012). An empirical study of determinants of e-commerce adoption in SMEs in Vietnam: An economy in transition. Journal of Global Information Management (JGIM), 20(3): 23-54.

Salwani MI, Marthandan G, Norzaidi M, and Chong S (2009). Ecommerce usage and business performance in the Malaysian tourism sector: Empirical analysis. Information Management and Computer Security, 17(2): 166-185.

Salwani MI, Marthandan G, Norzaidi M, and Chong S (2009). Ecommerce usage and business performance in the Malaysian tourism sector: empirical analysis. Information Management and Computer Security, 17(2): 166-185.

Santhanamery T and Ramayah T (2013). The effect of personality traits on user continuance intention of e-filing system. Journal of Economics, Business and Management, 1(1): 25-29.

Sekaran U and Bougie RJ (2016). Research methods for business: a skill building approach. John Wiley \& Sons, New York, USA.

Sin YK, Osman A, Salahuuddin NS, Abdullah S, Lim JY, and Sim LC (2016). Relative advantage and competitive pressure towards Implementation of E-commerce: Overview of small and medium enterprises (SMEs). Procedia Economics and Finance, 35: 434-443.

Soares-Aguiar A and Palma-DOS-Reis A (2008). Why do firms adopt e-procurement systems? Using logistic regression to empirically test a conceptual model. IEEE Transactions on Engineering Management, 55(1): 120-133.

Tan K, and Eze U (2008). An empirical study of internet-based ICT adoption among Malaysian SMEs. Communications of IBIMA, 1(1): 1-12.

Thong JYL (1999). An integrated model of information systems adoption in small businesses. Journal of Management Information Systems, 15(4): 187-214.

Thong JYL (2001). Resource constraints and information systems implementation in Singaporean small businesses. Omega, 29(2): 143-156.

Tornatzky LG and Fleischer M (1990). The process of technology innovation. DC Heath \& Company, Lexington, USA.

Turban E, Volonino L, and Pollard C (2008). Information technology for management: Transforming organizations in the digital economy. John Wiley \& Sons, NJ, USA.

Wang YM, Wang S, and Yang F (2010). Understanding the determinants of RFID adoption in the manufacturing industry. Technological Forecasting and Social Change, 77(5): 803-815.

Whittaker S, Bellotti V, and Gwizdka J (2006). Email in personal information management. Communication of the ACM, 49(1): 68-73.

Yap SC (1990). Distinguishing characteristics of organizations using computers. Information and Management, 18(2): 97107.

Zhu K and Kraemer KL (2005). Post-adoption variations in usage and value of e-business by organizations: cross-country evidence from the retail industry. Information System Research, 16(1): 61-84.

Zhu K, Kraemer KL, and Xu S (2006). The process of innovation assimilation by firms in different countries: A technology diffusion perspective on e- business. Management Science, 52(10):1557-1576. 